\title{
Health in the NHS: lifestyle behaviours of hospital employees
}

Holly Blake ${ }^{1}$, Phoenix K. H. Mo², Sandra Lee ${ }^{3}$ and Mark E Batt ${ }^{3}$

${ }^{1}$ University of Nottingham; ${ }^{2}$ Chinese University of Hong Kong; ${ }^{3}$ University of

Leicester; ${ }^{4}$ Nottingham University Hospitals NHS Trust

Citation: BLAKE, H, MO, P.K.H, LEE, S and BATT, M.E., 2012. Health in the

NHS: Lifestyle behaviours of hospital employees Perspectives in Public

Health. 132, 213-215.

\section{Introduction}

Whilst recent UK government publications have called for NHS staff to 'set the example' as role models for the health of the general public, ${ }^{1,2}$ previous work has suggested that many NHS staff engage in negative health behaviours. ${ }^{2,11}$ This is important, not least with regards to the health of the individuals concerned, but also has implications for patient care, since the health practices of healthcare staff has been associated with their tendency to raise health behaviour issues with their patients and clients, ${ }^{3}$ and healthcare staff personally feel that their own health behaviours affect the quality of the patient care they deliver. ${ }^{2}$ Sickness absence rates are high amongst NHS employees and are known to be greater in the NHS compared with other sectors. ${ }^{2,4}$ For those who are not absent but in poor health, work 'presenteeism' is a key issue affecting productivity, ${ }^{5}$ and these factors all have a concomitant financial burden on NHS resources. ${ }^{2,6}$ There is a need to further understand the health and wellbeing profile of NHS employees in order to inform effective targeting of interventions to support them in making healthy lifestyle choices. 


\section{Methods and Results}

All NHS employees based on a single acute NHS teaching hospital campus were invited to take part in a questionnaire survey $(n=7,085)$ to assess baseline health and wellbeing of NHS employees prior to the development of a workplace wellness intervention. The questionnaire has been described previously, ${ }^{7}$ and included demographic information (age, gender, height and weight), physical activity level and barriers to physical activity, self-efficacy for physical activity, knowledge of physical activity, social support for physical activity and participation in recreational and sport activities. A metabolic equivalent of task (MET) for recreational and sport activities was calculated for each participant. Perception of general health and mood status, smoking behaviour (cigarette or pipe), dietary behaviour (5-a-day, consumption of foods high in fat or sugar, drinking eight glasses of water per day, and employees were asked to indicate whether they considered that they ate healthily at the time of the study). The survey also included items related to self- efficacy for healthy eating and social support for healthy eating, perceived work performance and self-reported sickness absence.

Ethical approval was gained prior to the study commencing, together with approval from local NHS R\&D. Questionnaires were distributed to all employees via their payslips and informed consent was taken to be return of the form via the internal mail system, within a specified period of four weeks. Data was entered into SPSS for Windows 13.0 and a 10\% data check was conducted. Responses were received from 1,452 employees (21\%), with a demographic profile comparable with that of the local NHS Trust. The mean age 
of employees was 41 (SD=11.2, range 17-72) years. There were 297 male (20.5\%) and 1155 female respondents (79.5\%). Most of the employees were from nursing (38.2\%) and administrative or clerical categories (25.5\%), which represented the largest occupational groups within the Trust.

Just under a third of employees (30\%) reported that they were sedentary ('not very' or 'not at all' active) at work. In the previous week, $31 \%$ reported that they had actively travelled to the workplace. Almost half of the employees (45.2\%) did not meet the physical activity guidelines for the benefit of health at that time: '30 minutes of moderate activity on most days of the week'. 1 The most common reported barriers to engaging in physical activity were not having time to be physically active (62.6\%), followed by feeling tired (34.1\%), and a lack of motivation $(23.7 \%)$.

Based on the 2006 classification of the World Health Organization, $43 \%$ of the employees were classified as overweight or obese $(30.3 \%$ and $12.9 \%$ respectively). One-tenth of employees (10.6\%) indicated low mood on the GHQ12; more than one-third of employees (40.4\%) reported they did not have seven hours of sleep, more than half of the time. Approximately one-tenth $(10.4 \%)$ of the sample reported that they were current smokers. More than half (56.5\%) of employees reported they did not consume five servings of fruit or vegetables per day. More than one-third of the employees reported they ate foods high in fat and sugar at least once a day (30.4\% for once a day and $7.0 \%$ for $2-3$ times a day). Only $22 \%$ of employees reported that they drank eight glasses of water a day. However, more than two-thirds of the employees (70.4\%) felt that they were eating healthily at the time of study. Most 
of the employees $(92.6 \%)$ reported they were satisfied with their overall performance at work. There were $4.6 \%$ of employees who indicated they had taken sickness absence within the past month.

Those participants who met the recommended daily guidelines for physical activity ('active') were compared with those who did not ('inactive'). Active employees reported a significantly higher level of MET for recreational and sports activities each week $(M=5.37, S D=12.77$ for active employees, $M=1.94$, $\mathrm{SD}=10.08$ for inactive employees), $\mathrm{t}(1397)=5.5, \mathrm{p}<.001$. They also scored significantly higher in self efficacy for physical activity $(M=1.19, S D=.52$ for active employees, $\mathrm{M}=.76, \mathrm{SD}=.46$ for inactive employees $), \mathrm{t}(1388)=16.08$, $\mathrm{p}<.001$, and social support for physical activity $(\mathrm{M}=1.58, \mathrm{SD}=.1 .07$ for active employees, $\mathrm{M}=1.17, \mathrm{SD}=.93$ for inactive employees), $\mathrm{t}(1358)=7.53, \mathrm{p}<.001$, than inactive employees. Chi-square tests showed that inactive employees were more likely to report more barriers to engaging in physical activity than active employees. Active employees ( $M=2.50, S D=.95)$ reported significantly higher scores in general perception of health than the inactive employees $(M=2.07$, $\mathrm{SD}=.96), \mathrm{t}(1381)=8.46, \mathrm{p}<.001$. They were also less likely to be classified as overweight or obese, $\chi 2(3)=20.21, p<.001, \chi 2(3)=20.21, p<.001$, less likely to demonstrate low mood on the GHQ-12, $\chi 2(1)=14.81, \mathrm{p}<.01$, and were more likely to get seven hours of sleep per day, $\chi 2(3)=8.58, p<.01$. Active employees were less likely to smoke than inactive employees, $\chi 2(1)=3.84, p<.01$. Physically active employees were more likely to eat five servings of fruit/vegetable every day, $\chi 2(2)=28.85, p<.001$, more likely to drink eight glasses of water a day $\chi 2(2)$ $=24.42, \mathrm{p}<.01$, and more likely to report eating healthily, $\chi 2(1)=28.2, \mathrm{p}<.001$ than their inactive counterparts. Active employees $(M=1.53, S D=1.11)$ also 
reported significantly increased social support for eating healthily compared with inactive employees $(\mathrm{M}=1.31, \mathrm{SD}=1.02)$

\section{Discussion and Conclusion}

Our findings demonstrate that poor health behaviours are still prevalent amongst NHS employees, and supports the notion that health behaviours 'cluster' together (e.g. those who are more active are also more likely to engage in other healthy behaviours, and vice versa). Based on their self-reporting, nearly half the employees in this study were not physically active enough for the benefit of their health; although levels of physical activity were better than general population figures, there remains a high percentage of inactive NHS employees. Almost half of our sample was either overweight or obese; whilst obesity rates were slightly lower than the general population, rates of overweight were comparable. Although the majority of employees believed they ate healthily, more than half reported that they do not consume the recommended daily intake of fruit or vegetables (5-a-day), with over a third of employees reporting regularly eating foods that were high in fat and sugar content. One-fifth of employees in this study did not report consuming the recommended daily intake of water (suggested by the UK Food Standards Agency) yet adequate hydration is known to be an important factor in health, wellbeing and performance whilst at work. Whilst a range of occupational reasons have been proposed for low levels of physical activity and poor dietary habits, including long/irregular working hours, shift work, high levels of stress/ burnout and staff turnover, the NHS workplace environment could do more to facilitate healthy lifestyle choices. This is particularly important given that the Royal College of Physicians (RCP) and the 
Faculty of Occupational Medicine have found that only 15\% of NHS trusts had a policy or plan to help combat staff obesity.

Forty per cent of our sample reported that they did not regularly get seven hours of sleep yet the evidence suggests that sleeping less than seven hours per night may be linked to an increased risk of obesity, high blood pressure, diabetes, stroke and some cancers.

One-tenth of staff were smokers which is considerably lower than the national smoking prevalence figure for the general adult population in the UK, which was reported to be around $21 \%$ for 20078 and continues to decline.

Whilst most of the employees were satisfied with their work performance, $4.6 \%$ reported taking sickness absence within the past week; a figure comparable with the average sickness absence rate (4.5\%) reported in the NHS at this time ${ }^{9}$. Given that healthcare employees are perceived as important role models for health behaviours for the general public ${ }^{2}$ these findings are of concern and warrant immediate workplace wellness intervention to improve health behaviours in the NHS workforce.

Consistent with barriers identified in the general population, 'lack of time' was identified as the main barrier to physical activity participation in these NHS staff. This might be addressed in practice by helping people to build activity into their daily lives, particularly at their place of work. In addition to providing facilities for exercise and structured physical activity in the workplace, this might simply include encouragement for, and promotion of incidental physical activities such as brisk walking, increasing daily step counts through pedometer challenges, promoting stair-use and promoting cycling and walking to work. Managerial support should be provided for being active at work, and this may also include 
policy changes, for example, protecting work breaks. In this way, physical activity may be perceived as more accessible and achievable to healthcare staff within the working day.

Although the response rate was low, it is greater than other large surveys of workplace health ${ }^{10}$ and the sample was demographically representative of the population from which it was drawn. The health profile of non-responders is not known; yet the known tendency to over rather than under-estimate engagement in positive health behaviours, means the result is likely to be a poorer health behaviour profile than that presented here, and thus the practice implication remains unchanged. These findings, taken together with the clear recommendations of the Boorman Review, ${ }^{2}$ and the wide acceptance that workplace wellness is viewed by many as a corporate social responsibility, we recommend the development of workplace wellness interventions targeting multiple health behaviours, to support employees in adopting healthier lifestyle choices with appropriate provision made available within the NHS workplace setting.

\section{Acknowledgements}

We would like to thank Sport England for providing S.Lee at Nottingham University Hospitals NHS Trust with the survey measures used here.

\section{References}

1. Department of Health. (2004). Choosing health: Making healthy choices easier. London, UK: The Stationary Office. 
2. Department of Health. (2009). NHS health and wellbeing review: Interim report. London UK: The Stationary Office.

3. McDowell, N., McKenna, J., \& Naylor, P. J. (1997). Factors that influence practice nurses to promote physical activity. British Journal of Sports Medicine, 31(4), 308-313.

4. Blaber, A. Y. (2005). Exercise: Who needs it? British Journal of Nursing, 14(18), 973-975.

5. Stolk CV, Starkey T, Shehabi A, Hassan E. (2009). NHS Workforce Health and Wellbeing Review. Staff Perception Research, August 2009. Prepared for the Department of Health.

6. Williams, S., Michie, S., \& Pattani, S. (1998). Improving the health of the NHS workforce: report of the Partnership on the health of the NHS workforce. Technical report. London, UK: Nuffield Trust.

7. Malik S, Blake H, Batt M. (2011). How healthy are our nurses? New and registered nurses com- pared. Br J Nurs. 2011 Apr 28-May 12;20(8):489-96. 8. Office for National Statistics. (2007). General Household Survey: Smoking and drinking among adults. Available at http://www.statistics.gov.uk (last accessed $16 / 10 / 09)$

9. Department of Health. (2006). Results of the NHS Sickness Absence Survey. London: The Stationary Office.

10. Prodaniuk, T. R., Plotnikoff, R. C., Spence, J. C., \& Wilson, P. M. (2004). The influence of self- efficacy and outcome expectations on the rela- tionship between perceived environment and physical activity in the workplace. The International Journal of Behavioral Nutrition and Physical Activity, 1(7). 
11. Blake H, Malik S, Mo PK, Pisano C. (2011). 'Do as say, but not as I do': are next generation nurses role models for health? Perspect Public Health,

Sep;131(5):231-9. 